\title{
The effect of nonpatterned sensory deprivation on visual recognition thresholds
}

CHARLES M. FRIEL AND LEONARD DEROGATIS

THE CATHOLIC UNIVERSITY OF AMERICA

\begin{abstract}
Abstraet
A group of 18 college students underwent $50 \mathrm{~min}$. of nonpatterned sensory deprivation after which they were asked to identify four letter nouns given them at various exposure times. It was found that this group could recognize significantly more words at a faster exposure time than could a similar group not exposed to deprivation. It was concluded that the period of deprivation worked to increase the perceptual acuity of the deprived group.
\end{abstract}

\section{Problem}

In recent years, a great deal of interest has been shown in the area of sensory deprivation because of the unique advantage of this technique in studying perceptual and cognitive processes. From the literature that has been published in the area, there seem to be two conflicting theoretical positions emerging. Several researchers (Heron, Bexton, \& Hebb, 1953; Bexton, Heron, \& Scott, 1954; Heron, 1957) have found that periods of nonpatterned deprivation effect a generalized deficit in cognitive and perceptual functioning. Theoretically, they explain this impairment on the basis of Hebb's notion that disturbances in physiological and/or psychological functioning are due to lack of stimulation of non-specific arousal systems in the brain stem (Hebb, 1955). Thus, the decreased functional acuity following periods of nonpatterned deprivation is seen to be a result of a lowering of the generalized drive which energizes normal perceptual functions.

On the other hand, Vernon \& Hoffman (1956) and Osminston (1958) have found that periods of complete sensory deprivation result in higher levels of cognitive and perceptual functioning. This has been explained as a result of an increasing "hunger" for stimulation, as the period of deprivation increases. This accumulating "stimulus hunger" apparently brings the organism to a more sensitive level of perceptual functioning.

In answer to this theoretical issue, Rosenbaum, Dobie, \& Cohen (1959) did a study to determine if nonpatterned deprivation decreases perceptual acuity, as Heron and Bexton's work would indicate, and whether complete sensory deprivation increases perceptual acuity as Vernon, Hoffman and Orminston's work would indicate.

They found no differences between the visual recognition thresholds of Ss subjected to both forms of deprivation. However, because nondeprived control groups were not used, it is still difficult to determine whether deprivation in itself raises or lowers thresholds.
The present study is designed to compare the visual recognition thresholds of a nonpatterned deprivation group and a nondeprived group, predicting that the deprived group will show greater perceptual acuity than the nondeprived group.

\section{Method}

The Ss were 38 students of the Catholic University of America, Washington, D.C.; 18 assigned to the sensory deprived group (SD) and 20 to the nondeprived group (NSD).

The deprivation room was equipped so that four letter nouns could be tachistiscopically projected on a screen $6 \mathrm{ft}$ from the $\mathrm{S}$, at the following rates: $1,3,6,10$, and $17 \mathrm{msec}$.

Each S of the SD group was exposed to $50 \mathrm{~min}$. of nonpatterned deprivation. This was achieved by having the $\mathrm{S}$ wear gonzfeld glasses illuminated to $4 \mathrm{ft}$-candles, a constant auditory input of white noise and requiring the $\mathrm{S}$ to move as little as possible. After $50 \mathrm{~min}$. of deprivation the $S$ was instructed that words would be projected on the screen in front of him atvarious speeds, and his task was to tell the experimenter whatever he thought the words were. Five different nouns were shown at each speed, making a total of 25 words shown to each $\mathrm{S}$. The same procedure was used with the NSD group, but without exposing them to a period of deprivation.

\section{Results}

Figure 1 shows the mean number of correctly recognized words for each of five exposure times. It can be seen that the SD group tends to recognize more words at smaller exposure times than the NSD group. A $t$ test between groups on the mean number of correctly recognized words at each exposure time revealed significant differences at the 3 msec. level $(t=4.50 ; p<.001)$.

\section{Disenssion}

It can be seen from Fig. 1 that the SD group could recognize words shown to them at a smaller exposure time than could the NSD group. Apparently, the $50 \mathrm{~min}$. of deprivation undergone by the SD group precipitated a state of greater perceptual acuity than was had by the NSD group. Theoretically, this can be explained by the notion that continued exposure to nonpatterned monotonous stimulation builds up a need in the organism for meaningful stimulation. Much in the same way as increasing the hunger drive alerts the organism to food related stimuli, increased "stimulus hunger" heightens the organism's perceptual acuity and readiness to perceive meaningful stimulation. Deficiences in per- 


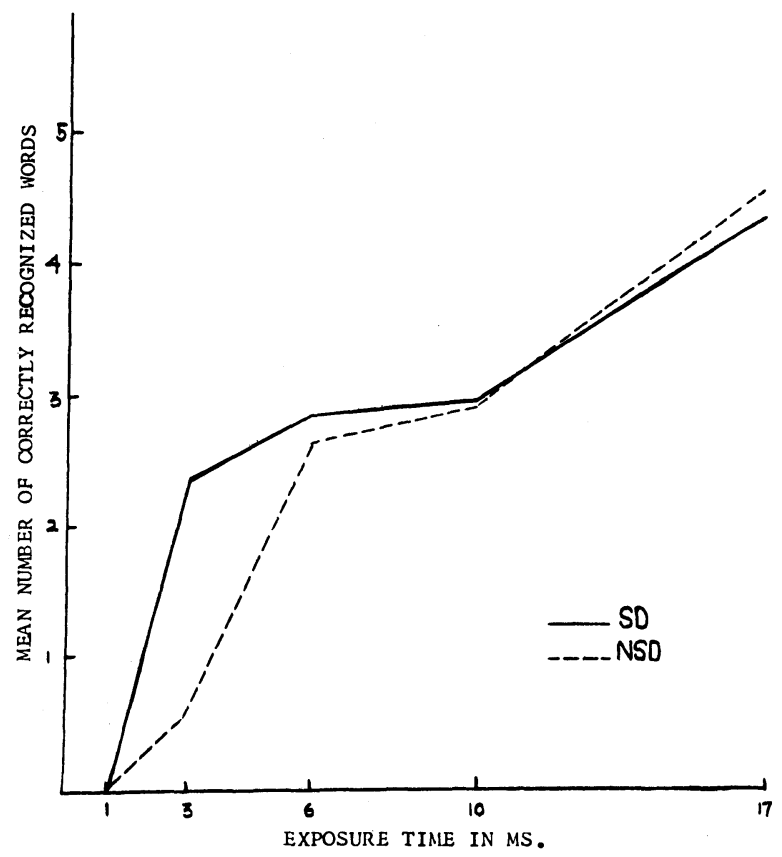

Fig. 1. Word recognition as a function of exposure time. ceptual acuity that are reported in the literature (Heron et al, 1953; Bexton et al, 1954; Heron, 1957) are more likely correlated with prolonged periods of deprivation that go beyond the point of maximum perceptual acuity to a point where the "stimulus hunger" has exhausted the organism's perceptual readiness resulting in substandard perceptual functioning.

\section{Referenees}

Bexton, W. H., Heron, W., \& Scott, T. H. Effects of decreased variation in the sensory environment. Canad. J. Psychol., 1954, 8,70 .

Hebb, D. O. Drives and the C.N.S. Psychol. Rev., 1955, 62, 243.

Heron, W. The pathology of boredom. Scient. American, 1957, 196, 52.

Heron, W., Bexton, w. H., \& Hebb, D. O. Cognitive effects of decreased variation in the sensory environment. Amer. Psychologist, 1953, 8, 366.

Orminston, D. N. The effects of sensory deprivation and sensory bombardment on apparant movement thresholds. Amer. Psychologist, 1958, 13, 389.

Rosenbaum, G., Dobie, S., \& Cohen, B. D. Visual recognition threshold following sensory deprivation. Amer. J. Psychol., $1959,72,429$.

Vernon, J. A., \& Hoffman, J. Effect of sensory deprivation upon rote learning in human beings. Science, 1956, 123, 1074. 